\title{
Formação de um habitus futebolístico em mulheres no Brasil: um relato a partir das vivências de infância e vida adulta
}

https://doi.org/10.11606/issn.1981-4690.V35i2p263-271

\author{
Leila Salvini* \\ Wanderley Marchi J únior*
}

*Universidade Federal

do Paraná, Curitiba,

$\mathrm{PR}$, Brasil.

\begin{abstract}
Resumo
0 presente escrito tem como objetivo identificar disposições iniciais à prática do futebol e a formação de um habitus futebolístico em mulheres, para tanto, foram realizadas quatro entrevistas semiestruturadas com jogadoras de uma equipe de futebol da cidade de Curitiba/PR que no decorrer de suas carreiras participaram de partidas oficiais defendendo a Seleção Brasileira de Futebol Feminino. Após análise das informações, concluímos que as disposições iniciais para a prática do futebol baseiam-se em seis etapas compartilhadas por todas as entrevistadas, e que as disposições necessárias para elas adentrarem o espaço do futebol não são as mesmas que as mantém nele.
\end{abstract}

Palavras-chave: Futebol Feminino; Sociologia do Esporte; Pierre Bourdieu; Brasil.

\section{Introdução}

A prática do futebol por mulheres vem sendo discutida por diversos autores ${ }^{1-6}$, e tem em suas raízes alguns temas recorrentes, entre eles o corpo, ou a apresentaçáo dele. Compreendendo que o futebol no Brasil ainda apresenta traços de certa "dominação masculina”, e que dessa forma, a entrada das mulheres nesse espaço perpassa pela aceitação dos agentes legítimos, o "velho mundo do futebol" está intimamente ligado aos elementos corporais que podem legitimar a atleta como feminina ou questionar sua sexualidade em detrimento à construçáo do seu corpo.

Esse corpo que exterioriza as preferências, as açôes, o modo de se portar e as escolhas, pode ser entendido por Bourdieu como habitus. Para o autor, o habitus é um corpo socializado, um corpo estruturado, um corpo que incorporou as estruturas imanentes de um mundo ou de um setor particular desse mundo, de um campo, e que estrutura tanto a percepção como a ação nesse mundo ${ }^{7}$.

O habitus funciona, portanto, como esquema de ação, de percepção e de reflexão encarnados no corpo e na mente de forma durável e com o contorno de disposiçóes permanentes por meio de gestos, posturas, formas de ver o mundo, de classificar a si próprio e classificar seus pares por meio de suas próprias classificaçóes. É algo adquirido e decorrente das estruturas sociais e históricas de cada agente. Nesse propósito, o habitus apresenta-se ao mesmo tempo como social e individual, reportando a sistemas de classificaçóes que são evidenciados pelas posiçóes sociais, nas quais, a estrutura objetiva de distribuição dos bens materiais e simbólicos na sociedade ocorre fundada em parâmetros de desigualdade ${ }^{8}$.

A discrepância que existe no Brasil ao abordarmos aspectos históricos, culturais e mercantis do futebol masculino ou feminino, instigou-nos a conhecer como as mulheres jogadoras de futebol iniciaram nessa prática. Embora ainda não sejam jogadoras profissionais, nossas entrevistadas depositam nessa modalidade o anseio por uma carreira de sucesso, que mesmo nos dias atuais ainda é vislumbrada pelo senso comum como uma prática esportiva direcionada ao público masculino. Nesse contexto, nosso objetivo com esse artigo é identificar as disposiçôes iniciais à prática do futebol que atuam como uma frente de formação de um habitus futebolístico em mulheres. 


\section{Método}

A fim de atender ao objetivo, foram entrevistadas ${ }^{\mathrm{a}}$ quatro jogadoras de uma equipe de futebol feminino da cidade de Curitiba/PR que nos últimos cinco anos (considerando o ano de 2014) tiveram pelo menos uma atuação pela Seleção Brasileira de Futebol Feminino. A equipe em questão foi escolhida pela grande quantidade de títulos conquistados e por ter em seu quadro de atletas, jogadoras que já tiveram passagem pela Seleçâo Brasileira de Futebol Feminino, dessa forma, justificamos a escolha pela legitimidade da equipe do Novo Mundo Futebol Clube (NMFC) no cenário do futebol feminino paranaense e nacional.

As informaçôes oriundas das entrevistas, foram transcritas na íntegra e organizadas a partir das similitudes de temáticas abordadas, nesse caso em específico, consideramos as brincadeiras de infância, a presença do futebol na vida das jogadoras e como isso foi fazendo parte de seus dias e da formação de um conjunto de predisposiçóes para a ação no universo esportivo, o qual com base na teoria proposta por Pierre Bourdieu, foi compreendido como habitus esportivo o qual para esse artigo estamos chamando de habitus futebolístico.

Em termos de apresentação, as informaçôes aparecerão nesse escrito respeitando uma ordem cronológica, começando a abordagem por meio

\section{Resultados}

\section{Os primeiros contatos com o futebol}

Os relatos que remetem à história das meninas do NMFC sobre o seu início no futebol são muito parecidos com aqueles proferidos por Pretinha e Marta - jogadoras conhecidas nacionalmente - e apresentados por VALPORTO ${ }^{10}$. Tanto as jogadoras acima mencionadas, quanto as nossas entrevistadas, iniciaram a prática na infância, jogavam em equipes masculinas nas escolinhas ou, nas brincadeiras da escola e da rua eram as únicas meninas a participarem do jogo de futebol. A fim de ilustrar essa afirmaçáo, o autor traz a fala de Pretinha: "no começo achavam estranho porque eu era a única menina no meio da molecada. Mas depois todo mundo se acostumou"10 (p. 247).

Essa passagem esboça a realidade do espaço do futebol no Brasil, espaço de lutas, que de acordo com MARCHI JÚNIOR ${ }^{8}$ visam transformar ou conservar um campo, sua estrutura. Em se tratando do futebol, das brincadeiras de infância, passando pela escola e pelas escolinhas de futebol, e posteriormente, sob as implicaçóes da vida adulta na prática do futebol. E estão organizadas em dois subtítulos: Os primeiros contatos com o futebol e Enfrentamentos e êxitos no e com o futebol.

Antes de tecermos maiores apontamentos a cerca das disposições iniciais para a prática do futebol por mulheres, é importante destacar que estamos entendendo que o habitus de um agente é formado pela intersecção de diferentes vivências, oriundas - de também - diferentes espaços sociais, ou de acordo com Bourdieu, de diferentes campos. No entanto, para esse escrito estamos visualizando unicamente as possíveis influências do campo esportivo, do subcampo do futebol e da estrutura do futebol feminino na construçáo e manifestação de um habitus futebolístico em mulheres.

Vale ressaltar que na construção de seus conceitoschave (campo, habitus e capitais) Bourdieu' assinala a inexistência de um frente ao outro. Dessa forma, justificamos nossa escolha teórico-metodológica ao evidenciarmos a formação de um habitus futebolístico em mulheres sob as influências incorporadas e exteriorizadas - por meio de estratégias de ação - no campo esportivo e no subcampo do futebol.

entendido pela nossa cultura como um espaço de reprodução de significados de masculinidade, as mulheres que desejam fazer parte desse espaço se utilizam o que Bourdieu ${ }^{11}$ chama de estratégias de subversão ou heresia, que iniciam na infância quando as meninas tentam participar das atividades dos meninos, se prolonga pela adolescência quando buscam escolinhas para treinar e permanecem na vida adulta no futebol de alto rendimento, revestido pela falta de incentivo.

Essas estratégias para a entrada e consolidação nesse espaço, conflitam com os agentes dominantes, estabelecidos que monopolizam o capital específico e apresentam estratégias de conservação, dificultando ou impedindo a entrada de novos (nesse caso de novas) agentes. Veremos na sequência nos depoimentos das jogadoras que a luta por uma posiçáo legítima nesse subcampo é constante.

Em se tratando das jogadoras do NMFC, as quatro 
entrevistadas contam que começaram como uma brincadeira ainda na infância, e que, embora não fossem explicitamente incentivadas e motivadas a praticarem o futebol, tiveram o apoio de pelo menos um membro da família, o que foi decisivo para que continuassem na carreira esportiva. Nesse contexto elucidamos o entendimento de que o habitusé produto de uma história individual, de experiências formadas na infância, e também, é a história coletiva da família ${ }^{12}$, que nos leva a entender que a formação de um habitus futebolístico inicia nessa fase.

BouRDIEU $^{12}$ salienta que é no universo familiar que acontece a reprodução das práticas. Essa reprodução pode ser vislumbrada na história das jogadoras que tem entre os seus familiares praticantes do futebol, na maioria das vezes homens, fato que demonstra a soberania masculina nessa modalidade e, que por muito tempo, promoveu entre as praticantes de futebol a imitação de disposiçóes dos dominantes desse subcampo ${ }^{13}$.

O futebol praticado pelas mulheres no seu sentido mais amplo passou por um processo de modificaçóes, tanto no estilo de jogo, quanto nos uniformes e também na aparência física das próprias jogadoras. Remetendo-nos à história da modalidade contada pelas páginas da Revista Placar especialmente na década de 1990, chamamos a atençấo para a existência de dois "mundos" do futebol de mulheres. Um, praticado por atletas com destrezas físicas e habilidades técnicas que fizeram com que a modalidade fosse apreciada a partir das nuances de plasticidade do jogo e de performance e menos pela preocupaçáo em aparecer em campo reforçando atributos de beleza normativos. E o outro, o das modelos que jogavam futebol, as quais usavam uniformes muito diferentes daqueles dos times oficiais, deixando os corpos mais a mostra e reforçando os atributos normativos de feminilidade ${ }^{13,14}$.

Já nos anos 2000, o que foi possível constatar, também com vistas às publicações da Revista Placar, é que as jogadoras munidas de habilidades técnicas por diferentes fatores, dentre os quais, estão envolvidas questôes de patrocínios e também de veiculação dos jogos em televisão, passaram a adotar uniformes diferentes daqueles da década anterior. Como também foi reduzido o número de jogadoras que usavam cabelo curto ou raspado, outra evidência da existência de um processo de incorporação de atributos normativos de feminilidade. Tal fato, reforça o argumento de que o mercado esportivo funciona a partir de elementos que normatizam os corpos a fim de lhes conceder visibilidade e também patrocínios ${ }^{14}$.

Já nos anos 2000, o que foi possível constatar, também com vistas às publicaçóes da Revista Placar, é que as jogadoras munidas de habilidades técnicas por diferentes fatores, dentre os quais, estáo envolvidas questốes de patrocínios e também de veiculaçâo dos jogos em televisão, passaram a adotar uniformes diferentes daqueles da década anterior. Como também foi reduzido o número de jogadoras que usavam cabelo curto ou raspado, outra evidência da existência de um processo de incorporaçáo de atributos normativos de feminilidade. Tal fato, reforça o argumento de que o mercado esportivo funciona a partir de elementos que normatizam os corpos a fim de lhes conceder visibilidade e também patrocínios ${ }^{14}$.

Nessa esteira, o sentido do jogo que nasce com essas agentes e se intensifica no decorrer dos anos, é decisivo para legitimar a participação delas em um espaço de domínio masculino. Por na maioria das vezes terem brincado ou jogado com meninos, as entrevistadas contam que desenvolveram algumas estratégias de entrada nesse grupo, e, por conseguinte, de entrada no futebol.

A prática do futebol iniciada na infância apareceu na vida da jogadora 1 e da jogadora 2 como sendo uma segunda opçáo nas brincadeiras, tendo em vista $\mathrm{o}$ que lhes era ofertado naquele momento para brincar. A jogadora 2 atribui às brincadeiras com os primos $o$ primeiro contato com o futebol, e assim nos conta:
[...] eu sempre tive muitos primos, a maioria homens, e poucas mulheres e a maioria das brincadeiras eram voltadas para os meninos, e era sempre futebol, futebol, futebol e como eu queria brincar, acabava brincando de futebol e de polícia pega ladrão pela rua, pela falta de opção de brincadeiras. Eu tinha uns 15 primos e 3 primas, e sempre era mais interessante as brincadeiras deles. E eu acabei gostando, e aí que eu fui ganhando habilidade de jogo, comecei a saber um pouquinho mais.

Prosseguindo nessa esteira, a jogadora 1 relata que:

$$
\begin{aligned}
& \text { [...] No começo eu náo gostava de futebol, porque } \\
& \text { meu pai ficava assistindo na televisão e eu queria ver } \\
& \text { outra coisa. Mas, como ele continuava assistindo, eu } \\
& \text { comecei a assistir junto e depois do jogo pegava a bola } \\
& \text { e saia para brincar, tentava fazer embaixadinhas. Teve } \\
& \text { uma vez que eu tirei a cabeça de uma boneca para } \\
& \text { fazer de bola. }
\end{aligned}
$$

Frente a esse discurso, trazemos à tona que entre os irmãos somente a jogadora 1 sabia jogar, bem como, o consumo esportivo do pai (que já foi jogador) 
teve influência direta nas brincadeiras da filha, e podemos notar a menção à boneca como brinquedo classificado como divertimento feminino e que nesse contexto assume um papel de rompimento com os estereótipos de gênero ao trocar a boneca pela bola, ou principalmente pela cabeça da boneca que assumiria a função de uma bola.

Assim como a brincadeira com bonecas, o "brincar de casinha" também faz parte do "rol" de brincadeiras estimuladas às meninas, enquanto o futebol aparece como uma atividade não incentivada a esse público e muito praticada pelo público masculino, como elucidou a jogadora 2. Dessa maneira, evidenciamos a recusa desse estereótipo feminino nas práticas infantis na fala da jogadora 3 :

$\mathrm{Na}$ realidade eu nunca brinquei de casinha, eu nunca gostei de brincar, meu esporte preferido era estar com uma bola, eu brincava muito com os meninos, a minha base motora foi muito brincar com os meninos, entâo assim, eu brincava demais de esconde-esconde, de queima, sempre com os meninos, eu tinha mais contatos com os meninos do que com as meninas, sempre gostei disso e até hoje é assim.

A jogadora 3 enfatiza que sua "base motora foi muito brincar com os meninos", e nos subentende que as brincadeiras "de meninas" são mais estáticas, com movimentação reduzida. Esse depoimento promove um possível entendimento à falta de habilidade feminina em esportes entendidos como vigorosos, tendo em vista o pouco, ou reduzido, incentivo nas brincadeiras infantis.

Ainda que a modalidade estivesse presente na vida dessas meninas desde tenra idade (por volta dos sete anos), o apoio familiar, assim como a apreensáo que pairava sob essa prática, veio de diferentes frentes. A jogadora 4 relembra que com seis ou sete anos acompanhava sua avó nos jogos dos seus tios, que eram jogadores de futebol profissional, e que as práticas esportivas eram recorrentes em sua família, contudo, nos diz:

[...] meus tios falavam no começo que futebol era pra menino, e minha avó falou não, se ela gosta de futebol ela tem que jogar. Entáo a minha avó sempre me acompanhou, me levava nas pracinhas, me levava nos jogos, entáo eu digo que quem me ajudou sempre foi a minha avó.

As entrevistadas vivenciaram em suas infâncias o futebol feminino do início/metade dos anos 1990, período onde a sexualidade feminina era (e continua sendo, em menor proporção) posta à prova pelo desenho dos seus corpos e principalmente pela escolha da prática esportiva. Tendo em vista tais elementos, da mesma forma que os tios da jogadora 4, a máe da jogadora 1 também era contra a filha praticar o futebol, pois ela acreditava que o futebol masculinizaria seu corpo e suas práticas, alegando que as jogadoras de futebol eram homossexuais. Nas palavras da jogadora 1, "[...] minha mãe tinha preconceito, ela achava que futebol era coisa pra homem.

Dentre tantos fatores de cunho cultural que endossam o preconceito contra as mulheres que jogam futebol, podemos citar os questionamentos sobre a sexualidade dessas atletas. Como já apresentamos anteriormente, o futebol feminino no Brasil tem em sua história marcas nas quais a beleza física e a habilidade de jogo, nem sempre andavam lado a lado, dessa maneira, por não apresentarem em seus corpos o habitus feminino, ou apresentarem um habitus diferente ao estereótipo de feminilidade, a sexualidade dessas atletas era (e muitas vezes ainda é) posta à prova, pois, quando o padrão de corpo é rompido, tem-se a sexualidade questionada.

Mesmo frente esse panorama de questionamentos, a jogadora 2. fala que seus pais sempre the deram liberdade para escolher e praticar qualquer modalidade esportiva sem interferir e nem incentivar suas preferências.

Meus pais sempre me apoiaram muito, sempre deixaram fazer o que eu queria, nunca foram contra, tanto que minha máe que foi comigo me ajudar procurar uma escolinha. Mas assim, você ta fazendo por que você quer, não eram aqueles pais que vinham aos jogos, não eram aqueles pais motivadores. Eu fazia por que eu gostar, por gosto da prática, mas eles nunca me impediram.

A jogadora 3 enfatiza o apoio familiar que sempre recebeu para ingressar e permanecer no futebol:

[...] minha família foi muito importante, a minha estrutura de família foi muito importante, meu pai sempre me apoiou. [...] Eu sempre gostei, minha família sempre gostou e as coisas foram acontecendo. Eu comecei na minha cidade no interior do Paraná, comecei brincando com meninas sem treinamento, sem base nenhuma. Quando eu descobri que eu gostava de jogar futebol, surgiu uma escolinha chamada de Escolinha do Zico em Campo Mourão, uma escolinha só pra homens. Na época eu tinha 13 
anos e meu pai olhou pra mim e disse assim: por que você não vai atrás dessa escolinha? Eu disse: ah pai, mas é longe, mas ele disse: vai lá ver como é que é.

Além do apoio familiar para a prática do futebol outra questão comum ronda a história dessas (e de tantas outras) meninas futebolistas, o fato de adentrarem em um espaço tipicamente masculino e lutarem, no sentido de serem aceitas de forma legítima no grupo, seja nas brincadeiras de rua ou nas escolinhas de futebol. Tendo em vista que cada campo impóe um preço de entrada tácita e que determinados elementos desse jogo só tem valor pra quem está no jogo ${ }^{6}$, discorremos a seguir depoimentos das jogadoras que expressam açóes, ou estratégias que expressam o sentimento de legitimação nesse subcampo.

A jogadora 2 relembra os tempos de escola e de como ocorreu o processo de identificaçáo com o espaço do futebol em sua trajetória:

Nosso time (no primeiro ano do ensino médio) era muito bom no colégio, tinha menina que jogava na Seleção Brasileira, outras que já tinham passagem pela Seleçáo, a gente jogava os jogos colegiais e ganhava de $28 \times 0$, de $22 \times 0$, e com isso minha identidade com o futebol foi ficando mais forte. Daí nisso eu falei, vou procurar uma escolinha, quero jogar futebol, quero jogar futebol, era louca por bola, eu sempre jogava em praças.

Ela incita uma questáo muito interessante: a identificação com a modalidade, ou em suas palavras, "minha identidade com o futebol foi ficando mais forte". O sentimento de pertencimento ao espaço futebolístico pode ser vislumbrado na fala a seguir:

Escolinha não tinha muito na época, sempre jogava em Rua da Cidadania junto com meninos, mas como eu tinha um destaque um pouquinho mais, eu não era a menina que ficava excluída, eu tinha a opção, como acontece com muitas meninas que gostam e que às vezes náo tem oportunidade de jogar.

Essa declaraçáo deixa transparecer que a habilidade esportiva aparece como grande ferramenta legitimadora da entrada feminina no futebol, contudo, não minimiza os obstáculos enfrentados para prosseguir na carreira esportiva. No subtítulo a seguir, vamos tratar dos enfrentamentos para permanecer no espaço do futebol de modo a desenvolver os aspectos técnicos e dos êxitos conseguidos por meio dessa modalidade.

\section{Enfrentamentos e êxitos no e com ofutebol}

No discurso da jogadora 3 podemos observar o quáo difícil era uma menina praticar futebol de modo sistematizado em uma escolinha, ainda mais em se tratando de cidades pequenas do interior:

[...] E eu embarquei no ônibus com um dinheirinho na bolsa, não sabia como descia do ônibus, nunca tinha andado de ônibus, davam $120 \mathrm{~km}$ ida e volta. E eu cheguei lá, [...] só tinham meninos, tinha uma mulher, eu cheguei muito humildemente, quietinha ainda, e perguntei: tem pra mulher? Ai a mulher demorou um tempo, foi lá dentro e quando ela voltou, ela perguntou: é pra você? Eu falei é. Você quer se inscrever? Mas é só pra menino que tem. Eu disse: quero sim, fiz minha inscrição.

Ela ressalta que não tinha benefícios por ser menina e treinar com os meninos, e conta também que outras meninas procuraram a escolinha, mas não se adaptavam, ou nas palavras da entrevistada, não "aguentavam" os treinamentos:

[...] os professores não faziam diferença, isso foi muito bom na época, porque eu náo me senti privilegiada de estar treinando, eu simplesmente treinava o que eu conseguia, e normalmente conseguia tudo. Entáo eu não tinha diferenciaçãa, eu tinha sim, respeito de todos os meninos. [...]um ano depois que eu tava lá dentro eu comecei a ser referência pras outras meninas entrarem, elas entravam, mas não aguentavam muito, porque o treino do masculino é muito mais puxado que o do feminino, mas como eu já tava acostumada, pra mim já tava muito fácil.

A adequaçáo elucidada pela jogadora 3 ressalta a noção de que a mulher é fisiologicamente mais fraca que os homens e que deve se adequar ao treinamento, nos dando a impressão de que os meninos - embora sem preparo físico - já estivessem automaticamente adequados ao treinamento do futebol, pelo simples fato de serem do sexo masculino. Nesse caso, em termos hierárquicos dentro do futebol, rememoramos a passagem em que Bourdieu ${ }^{15}$ alega que, a biologia nos dá a impressão de estar na ordem das coisas.

Esse recorte deixa claro que embora ela fosse do sexo feminino, possuía características essenciais para o jogo, a persistência, o condicionamento físico, o 
combate e que se adequara àquela situação comum ao público masculino, legitimando-a enquanto jogadora na escolinha.

Outro estigma que revisita o espaço do futebol feminino com frequência é o do contato físico ou o da característica de combate. Considerando que o futebol feminino praticado em países da Europa ou nos Estados Unidos obedece às mesmas regras do praticado no Brasil, levantamos alguns subsídios hipotéticos para entender o discurso que alega o contato físico como fator limitador dessa prática ao público feminino.

O momento histórico (político e econômico) que o nosso país passava no início do século XX depositava na mulher o anseio pela renovaçáo populacional por meio da gestação e da manutenção da família. Os governantes disseminaram por meio do decreto 3.199 que o contato físico dos esportes (dentre eles o futebol) era uma ameaça à saúde feminina, logo, uma ameaça ao bom funcionamento da família e do Estado ${ }^{4,5}$.

Como subsídio para entendermos a censura do futebol praticado pelas mulheres, remontamos à noção de lutas dentro desse subcampo, lutas entre classes sociais e pela prática legítima para cada estrato social, pela a legitimidade do corpo feminino e de suas práticas esportivas legítimas, salientando que foram por quase 40 anos uma questão de Estado. Hoje, podemos arriscar que se trata de uma questáo de mercado, do mesmo modo que continua sendo uma questáo cultural ${ }^{14}$.

Nesse mesmo período, o futebol deixava de ser um entretenimento aristocrático e começava a fazer parte da preferência esportiva dos operários, promovendo a perda da distinçáo dessa prática. Ao passar do amadorismo - prática desinteressada e de lazer - para uma opção de trabalho, a modalidade perde o status e o prestígio dentre os agentes com maior capital econômico, e caracteriza-se como um gosto de classe popular isento de distinção, principalmente pelo contato corporal que assume.

Para BouRdieu ${ }^{12}$ a relação com o corpo embasa a escolha das práticas esportivas, pois, o envolvimento com o corpo se concatena a uma posição social e a uma experiência originária do mundo físico e social. Desse modo as práticas mais distintivas são aquelas que asseguram maior distância com o adversário, as mais estetizadas, aquelas nas quais a violência é menor ou inexistente, e aquelas em que a forma e as formalidades sobressaem sobre a força e a função. Somado a tais caracterizaçóes, classificamos o futebol como uma prática não distintiva, ainda mais se praticada por mulheres, poderíamos classificá-la como uma prática duplamente dominada: 1) pela relação com o próprio corpo e o contato com o adversário; e 2) por exigir das atletas açôes práticas no espaço do futebol opostas aquelas incentivadas e esperadas à hexis normativa feminina.

Ao fazer parte de um espaço historicamente marcado pela dominaçáo masculina em uma sociedade patriarcal, a mulher passa a agregar à sua imagem, elementos da cultura considerada como masculina, ou nas palavras de Bourdieu ${ }^{12}$, agrega ao seu habitus algumas disposiçôes para a ação do habitus masculino, pois, os agentes dominantes do espaço do futebol no Brasil são os homens. Embora ocorra essa incorporação ela não necessariamente atua modificando a sexualidade das futebolistas, contudo, ao assumir uma postura de gênero mais distante da central e posiçóes de poder em uma estrutura não familiar aos seus pares, causam aos dominantes desse subcampo, um olhar de reprovação e o questionamento da sua sexualidade.

BOURDIEU $^{15}$ nos ajuda a pensar esse repúdio dos homens contra a entrada das mulheres em determinados esportes - no caso brasileiro destacamos o futebol - como uma maneira de protegerem o "seu" espaço da feminilização, tendo em vista que as posiçóes sociais são sexuadas e sexualizantes.

Em termos de oportunidade, o futebol assume tamanha discrepância ao separarmos os gêneros, exigindo dessas "novas" agentes um esforço dobrado na busca por novas perspectivas no futebol. A luta da jogadora 3 por um espaço junto as oportunidades que o futebol oferecia aos meninos, ainda na sua adolescência, é apresentada na sequência:

Um dia eu vi um cartaz "clínica do Palmeiras [...] e eu fiquei sabendo logo em seguida que os meninos da minha cidade iam, ai eu fui, aonde tinha gente eu fui, revirei a cidade pra ir junto, no teste nós fomos no outro dia, com eles, e cheguei lá de novo com a mesma pergunta, posso fazer teste? Ele disse, só tem pra menino, quer fazer? Falei, quero, claro que sim. Dos 7 meninos que foram com a gente na Kombi só eu passei, essa foi a primeira clínica que eu fiz, depois e fiz mais 4 .

Com relação às participaçóes nas "clinicas", a jogadora 3 nos conta que somente pagou a primeira, e depois, não precisou pagar mais, ela justifica dizendo:

eu era a atração, uma menina pra chamar as outras meninas, eu deixei de pagar e eles pagavam pra mim as passagens pra ir pras clínicas deles. Fizeram quatro no Paraná e as 4 eu fui junto com ele, era 
um senhor de idade, quando deu um ano que eu fiz as clínicas com ele, ele disse: agora tá na hora de te levar pra jogar em São Paulo.

Diferente da jogadora 3, a jogadora 2, a jogadora 4 e a jogadora 1 começaram a treinar em escolinhas que tinham equipes femininas, mas cada qual com sua particularidade. "Fui procurar uma escolinha eu tinha uns 14 anos e achei o São Paulo Center, a JB, só que era sintético daí foi a minha primeira escolinha [...] Entrei com 15 anos, todas as meninas mais velhas que já jogavam já tinham experiência maior do que eu”, diz a jogadora 2 . A jogadora 4 relembra que:

[...] era sempre aquela mistura, tinha uma ou duas meninas, mas era muito difícil, sempre eu de menina, jogava na rua na praça eu nunca fiz escolinha quando era pequenininha eu sempre joguei com os meninos e fui pro time de menina com 12 anos, mas eu não podia jogar campeonatos por causa da idade.

Embora a jogadora 1 treinasse em escolinhas desde os 7 anos de idade, sua mãe não se posicionava a favor da prática, pois, para ela o futebol tinha função "masculinizadora", no entanto, "ela passou a me incentivar quando eu comecei a ter benefícios com o futebol", e nos conta:

[...] consegui muitas coisas com o futebol. Bolsa de estudos numa escola da cidade onde eu morava para jogar futsal para a escola, depois foi chamada para jogar no time de São José que hoje não existe mais, aí fui convidada para vir pra Curitiba jogar no Novo Mundo, também joguei futsal em Curitiba e ganhei uma bolsa para a faculdade de Educação Física.

A jogadora 2 também ressalta as oportunidades advindas com o futebol, em especial a bolsa de estudos para a graduação em Educação Física, assim como, a mudança que esses benefícios proporcionados pelo futebol influenciaram no apoio e na credibilidade dos seus pais frente a essa prática. Ela comenta que seus pais nem proibiam e nem

\section{Discussão}

Considerando as informaçóes coletadas por meio das entrevistas anteriormente apresentadas, pudemos concluir que as disposiçôes iniciais para a prática do futebol, e por consequência, a formação de um habitus apoiavam a presença dela no futebol, mas depois que perceberam que o futebol poderia "render alguns bons frutos" passaram a apoiar.

Pra mim o futebol me deu muitos frutos, não sei se eu que soube aproveitar isso [...] Eu fui lá, eu estudei, eu busquei, eu trabalhei. [...] então o futebol posso dizer que me deu muitas coisas, eu vivi um ou dois anos só de futebol, eu jogava e trabalhava, entâo eu não posso dizer que o futebol não me trouxe nada, trouxe muita coisa, muita coisa boa. Depois que os meus pais foram vendo que eu fui ganhando nome [...] no espaço do futebol, eles começaram a participar mais, hoje em dia meu pai é super participativo e super orgulhoso.

A jogadora 3, assim como a jogadora 2, agrega ao futebol a oportunidade de se formar na universidade e a chance de conhecer outros lugares do mundo, e relata,

[...] viajei países da Europa, da América Latina, do Brasil porque eu jogo futebol. Talvez se eu não tivesse jogado futebol eu não teria as oportunidades que o futebol oferece, indiretamente uma faculdade que já me formei, não sei se eu teria condiçóes de fazer essa faculdade se eu não fosse jogadora.

Em se tratando de carreira esportiva, entendemos de acordo com Bourdieu ${ }^{11}$, que é uma prática excluída do campo das trajetórias admissíveis a uma criança da burguesia - exceto esportes elitistas -, em contrapartida, representa uma forma de ascensão social para crianças de classes dominadas, como vimos nos relatos apresentados acima.

Assim como anteriormente apresentamos a fala da jogadora 3 sobre o empenho que teve para poder treinar, juntamente às declaraçóes sobre os ganhos com o esporte, remetemo-nos ao que Bourdieu ${ }^{16}$ identifica sobre os de gostos de classe, que estes se refletem nas práticas esportivas que por sua vez exteriorizam as disposiçóes incorporadas ao longo da vida, especialmente na infância.

futebolístico em mulheres consiste basicamente em seis etapas que embora distintas, permeiam umas as outras. Podemos considerar também, que quatro das etapas aconteceram no período da infância até a adolescência, 
e as outras duas etapas, da adolescência até a vida adulta, que serão cronologicamente abordadas na sequência.

Todas as entrevistadas compartilham dessas etapas, pois, tiveram o primeiro contato com a modalidade por meio de familiares, sejam tios, pais ou primos; jogavam futebol nas brincadeiras de rua; praticavam o futebol nas aulas de educação física escolar, e tanto nas brincadeiras de rua quanto na escola, destacavam-se pelo bom desempenho; procuraram escolinhas específicas de futebol, para aprimorarem a técnica; recebiam retorno financeiro (mesmo que irrisório) por partida jogada em eventos regionais, estaduais e nacionais; e por fim, destacam que foi por meio do futebol que tiveram oportunidades tanto de viajarem para o exterior para jogar, quanto de frequentarem um curso de graduação, no caso de três das quatro jogadoras, de educação física.

Ressaltamos que nas quatro etapas iniciais, ou seja, enquanto crianças, o capital social e físico era imprescindível para a permissão e estabelecimento das meninas nas brincadeiras na rua ou na escola, na grande maioria das vezes, em grupos liderados por meninos. No entanto, nas duas etapas posteriores, conforme o corpo feminino fora se desenvolvendo, as questôes relacionadas à hexis corporal das jogadoras, no sentido de apresentar um corpo que incorpora as características socialmente e culturalmente aceitas para o seu gênero, assumiram grande importância conjuntamente à noção da habilidade esportiva para a manutenção no espaço do futebol.

Nesse sentido, entendemos que a contribuição desse estudo para o universo do esporte praticado por mulheres vem a reforçar a existência da reprodução de açóes, e que, mesmo não compartilhando entre si os momentos de infância e adolescência, as jogadoras que nos cederam seus depoimentos, apontaram para a existência e recorrência de açóes similares, as quais orientam as condutas de proximidade como futebol no Brasil, nos fornecendo subsídios para crer na existência de um habitus futebolístico de mulheres que vai além dos limites geográficos ou financeiros das próprias jogadoras.

Somadas às ações ligadas à formação das jogadoras quando crianças e adolescentes, ressaltamos que na vida adulta, o campo esportivo, especificamente no que tange o funcionamento do subcampo do futebol feminino no Brasil, também reproduz algumas condutas, que não mais são escolhas das próprias jogadoras por afinidade à prática ou exacerbação de capacidades e habilidades de jogo, mas sim, o entendimento de que: ao seguir as orientações mercadológicas do funcionamento do campo esportivo - baseadas em atributos de normativos de feminilidades atrelados à habilidade física - a possibilidade de reposicionamento e também de manutenção como jogadora de futebol profissional nesses espaços torna-se ampliada.

\section{Nota}

a. As entrevistas semi-estruturadas ${ }^{17}$ duraram em média de 50 minutos tiveram o áudio gravado e foram realizadas nas dependências do clube entre os anos de 2010 e 2011 . Como a pesquisadora já realizava visitas a fim de observar o funcionamento dos treinos, tinha certa proximidade com as entrevistadas, por esse motivo, as entrevistas embora baseadas em 13 perguntas já determinadas, tiveram o tom amistoso de uma conversa. Cada entrevista aconteceu de maneira individual em horários previamente agendados a fim de que a contribuição advinda da história de vida das entrevistadas fosse facilitada. Antes da efetivação das mesmas, o roteiro de entrevistas foi aprovado pelo comitê de ética da Universidade Federal do Paraná registrado sob o protocolo número: 1050.175.10.11 e um termo de consentimento livre e esclarecido foi assinado por cada uma das entrevistadas. A fim de preservar a identidade das jogadoras, quando nos referirmos a elas no decorrer deste escrito, seus nomes serão substituídos por "jogadora 1", "jogadora 2", "jogadora 3" e "jogadora 4". 


\section{Abstract}

Training of a social habitus in women in Brazil: a report from the lives of childhood and adult life

This writing aims to identify initial provisions to soccer practice and the formation of a habitus of soccer in women, therefore, were conducted four semi-structured interviews with players of a football team from Curitiba / PR that throughout their careers participated in official matches defending the Brazilian National Women's soccer. After analyzing the information, we conclude that the initial arrangements for the practice of soccer are based on six steps shared by all interviewees, and that the necessary arrangements for them to step into the space of soccer are not the same as it maintains.

KEYWORDS: Women's Soccer; Sociology of Sport; Pierre Bourdieu; Brazil.

\section{Referências}

1. Mourão L. Representação social da mulher brasileira nas atividades físico-desportivas: da segregação à democratização. Movimento. 2000;13:5-18.

2. Moura EJL. As relaçóes entre lazer, futebol e gênero. [dissertação]. Campinas (SP): Universidade Estadual de Campinas, Faculdade de Educação Física, 2003.

3. Franzini F. Futebol é "coisa para macho"?: pequeno esboço para uma história das mulheres no país do futebol. Rev Bras Hist. 2005;25:315-328.

4. Goellner SV. Mulher e esporte no Brasil: entre incentivos e interdiçóes elas fazem história. Pensar Prát. 2005;8:85-100.

5. Goellner SV. Mulheres e futebol no Brasil: entre sombras e visibilidades. Rev Bras Educ Fís Esporte. 2005;19:143-51.

6. Rigo LC et al. Notas acerca do futebol feminino pelotense em 1950: um estudo genealógico. Rev Bras Ciên Esporte. 2008;29:173-188.

7. Bourdieu P. Razóes práticas. Campinas: Papirus, 1996.

8. Marchi Júnior W. “Sacando” o Voleibol. São Paulo: Hucitec, 2004.

9. Bourdieu P, Wacquant L. Una invitación a la sociología reflexiva. Buenos Aires: Siglo XXI Editores Argentina, 2005.

10. Valporto O. Atleta, substantivo feminino: vinte mulheres brasileiras nos Jogos Olímpicos. Casa da Palavra, Rio de Janeiro, 2006.

11. Bourdieu P. Questões de sociologia. Rio de Janeiro: Marco Zero, 1983.

12. Bourdieu P. Coisas Ditas. São Paulo: Brasiliense, 1999.

13. Salvini L, Marchi Júnior W. Notoriedade mundial e visibilidade local: o futebol feminino na revista Placar na década de 1990. Soc Plu. 2013;1:144-159.

14. Salvini L. Novo Mundo Futebol Clube e o "velho mundo" do futebol: considerações sociológicas sobre o habitus esportivo de jogadoras de futebol. [dissertação]. Curitiba (PR): Universidade Federal do Paraná, Departamento de Educação Física, 2012.

15. Bourdieu P. A dominação masculina. Rio de Janeiro: Bertrand Brasil, 2007.

16. Bourdieu P. A distinção: crítica social do julgamento. Porto Alegre: Zouk, 2008.

17. Flick U. Métodos qualitativos na investigação científica. 2. ed. Editora Monitor, 2005.

ENDEREÇO

Leila Salvini

Rua Coração de Maria, s/ $n$ 80210-132 - Curitiba - PR - Brasil E-mail: leila.salvini@hotmail.com
Submetido: 22/09/2014

Revisado: 09/ 10/2018

Aceito: 24/05/2021 